\title{
Method and device increasing efficiency of drilling directional wells
}

\author{
Spasibov Victor Maksimovich, Raspopov Roman Vladimirovich \\ Cybernetic Systems department \\ Tyumen Industrial University \\ Tyumen, Russia \\ romanraspopov@gmail.com
}

\begin{abstract}
The main independent controllable parameters in drilling oil and gas wells are the weight on bit and the frequency of bit rotation. When drilling deep directional wells with horizontal sections of the wellbore, the weight comes to the bottomhole with a delay due to increased frictional forces during the movement of the drill string to the bottomhole. This complicates the drilling control procedure. There are the methods of autonomous control of the weight on bit using electrical drilling, downhole motor, and the bit feeders. The research has shown that all known methods can generally only supplement the conventional method of creating weight on bit transmitting the weight of the compressed part of the drilling tool and formation of hydraulic force on the downhole motor shaft. Each of those methods has certain shortcomings and does not solve the problem entirely. This paper presents the method and the device that are most effective for drilling directional wells. It is achieved by generating an additional weight on bit in the device, transferring this weight and the part of the force from the drill string through the upper end of the downhole motor shaft to the bit. Reduction of the frictional forces of the drill string against the borehole wall is carried out by the constant transmission of the bit axial vibrations from the upper end of the shaft of the downhole motor to the drill string and by adjustment of the axial vibrations parameters.
\end{abstract}

Keywords—drilling; directional wells; bit; weight on bit; device; control.

\section{INTRODUCTION}

One of the unsolved current problems of deepening oil wells is the control of weight on bit (WOB) and the bit rotary speed with regard to their change in a dynamic mode [1].

When drilling directional wells with wide inclination angle and horizontal segments, the problem is worsened due to increasing frictional forces during the movement of the drill string and the delay of load transmission to the borehole bottom [2].

This problem was previously solved by the use of wellhead regulators of drilling mud pulsations; pneumatic compensators installed on the drilling pumps; by the difference in rotation frequency of the drill pump shaft and the downhole motor shaft; by changing the drilling mud flow rate; by the use of downhole regulators of the drill bit rotary speed [3], shock absorbers, rotating mass on the downhole motor shaft, centralizers, drill string separators, amplifiers of dynamic WOB, reduction devices, generators of drill string lateral vibrations and others [4, 5].

The research showed that all of the methods can only be complementary to the conventional method of increasing WOB - through the mass transfer of the compressed part of the drill string to the bit and through the formation of the hydraulic force on the downhole motor shaft at the designed pressure drop values in downhole motor and washing unit of the bit [6]. It means that in the absence of the reliable communication channel between the surbottomhole and the bottomhole, the problem is not solved entirely.

The aim of this research was to develop the method of increasing directional drilling performance.

\section{THE METHODS OF CREATING WEIGHT ON BIT}

Drilling deep wells usually uses the methods of autonomous control of the WOB with electrical drilling, with downhole hydraulic motor and bit feeders [7, 8].

In the case of electrical drilling, WOB is formed by feeding the drill string to the bottom and creating a hydraulic force only from the effect of the pressure drop in the bit. As a result, between the drill string feeds and the bottom, especially in the horizontal sections of the well, WOB can be reduced to a zero level [9]. In this case, the device, including the drill string with an integrated electrical cable [10] attached to the electric downhole motor and bit subs, has certain drawbacks:

- there is no mechanism for transferring axial forces from the drill string to the upper ends of the electric motor shaft and its spindle, and ther is no backward transmission of the axial vibrations of the bit; the latter is necessary to reduce the frictional forces of the drill string, lying on the bottom wall of the well, and to effectively transmit the load on the bit, especially between feeding the drill string and the bottom;

- there are no mechanisms in the device for creating an axial hydraulic force on the bit, except for the flushing unit of the bit; as a result, WOB can be reduced to zero between drill string feeds and the bottom;

- creating WOB is complicated because of heavy-weight drill pipes designed to carry the electric cable inside. 
The methods of the axial load transmission on the bit with the use of WOB control mechanism are practically not realized in an industrial scale because of their inherent drawbacks. However, the method for drilling a well with a downhole feed mechanism (DFM), built in between a drill string and a motor, was an exclusion. WOB is created by loading the bit with the weight of the motor and the moving part of the DFM, and also by creating hydraulic axial force from the effect of the pressure drops in the motor and the bit. In this method of creating WOB, the mass of the drill string does not participate in creating the load which remains constant, but this works only for the vertical wells. If there are inclined sections of the well, only the hydraulic force remains constant, i.e. in such conditions the method using DFM is inapplicable. Almost the same drawbacks are inherent in other ways of creating WOB with the use of various bottomhole DFMs, but with even greater complications in the design of the DFM.

When drilling deep wells with hydraulic downhole motor, WOB is formed by discrete and forced feed of the drill string to the bottom, by transferring the axial force partially or entirely from the drill string through the housing and the axial bearing of the motor and then through the lower part of its shaft to the bit. Another part of the designed WOB is created by generating a hydraulic axial force in the motor and in the flushing unit of the bit and transferring this part of the axial load along the motor shaft and then directly to the bit. The formation of such hydraulic force makes it possible to partially compensate for WOB that decreases between the drill string feeds to the bottom.

This method has drawbacks which are especially significant when drilling horizontal sections of the well:

- there is no mechanism in the drill string that would allow the lower part of the drill string to be fed to the bottom, create additional forces on the downhole motor shaft, and largely compensate for the reduction of WOB between the drill string feeds to the bottom; this is necessary when drilling the wells with inclination angles greater than 30 degrees and horizontal sections of the wellbore, when WOB is reduced to zero;

- there is no mechanism for transferring the axial vibrations of the bit from the top end of the downhole motor shaft to the lower part of the drill string.

The downhole motor shaft moves (relative to its housing) to the bit between the drill string feeds to the bottom. The intensity of the power contact between these motor nodes in the axial direction decreases for some time which results in a decrease in the energy level of the bit vibrations transmitted back to the drill string lying on the bottom wall of the borehole. The drill string is relatively calm during this period of time when the frictional forces between the string and the borehole wall significantly increase. This leads to the necessity of overcoming the increased forces of movement resistance during the next drill string feed to the bottom which also leads to erratic formation of WOB.

The intensity of backward transmission of axial vibrations from the bit to the drill string decreases when the axial bearing of the hydraulic downhole motor is unloaded between the drill string feeds to the bottom, this is the case of drilling horizontal sections of the well. Thus, the frictional forces between the drill string and the borehole wall and friction of the axial bearing of the downhole motor lead to erratic formation of WOB, early wear of the motor and the bit, and often to unplanned crooking of the well axis [11].

The research on this problem is carried out in Tyumen Industrial University. The task is to increase the power transmission to the bottom and to reduce the costs of drilling. As a result, a method is being developed which provides generating an additional hydraulic axial force in the valve of the device transmitting this force through the elastic element and transmitting a part of the force from the drill string to the upper end of the downhole motor shaft and then to the bit. The reduction of the frictional forces between the drill string and the borehole wall is carried out by the constant transmission of the axial vibrations of the bit from the upper end of the downhole motor shaft to the drill string and by adjusting axial vibrations parameters. The device is intended for drilling directional wells with wide inclined angles and with horizontal sections of the wellbore.

The developed method for forming WOB is as follows. During the drilling process, the upper and lower parts of the drill string are fed to the bottom. The hydraulic load on the downhole motor shaft (associated with the pressure differences in the motor and bit) is balanced with a part of the weight of the drill string. Part of the axial force from the drill string is transmitted to the axial bearing of the downhole motor, simultaneously through the additional axial sliding bearing, the spring, the hub of the device and the traverse axial vibrations are transmitted from the upper end of the motor shaft to the drill string. This reduces the friction of the drill string against the wall of the borehole and forms the axial load of the designed level.

To realize the proposed method of forming an axial load, the following components are installed in additional flow axial sliding bearing coaxially mounted in the sub between the hydraulic motor shaft and the drill string: an elastic element (for example, a steel coil spring) that smoothly transfers axial forces from the drill string to the upper end of the downhole motor shaft; steel bushing which provides a rigid transmission of axial vibrations from the upper end of the motor shaft to the drill string; a generator (for example, a plate valve) of the axial hydraulic force transmitted to the upper end of the hydraulic downhole motor shaft.

The scheme of the device for forming WOB (DFWOB) is shown in figure 1.

DFWOB works as follows. After the installation of toe step 1 and the whole device onto downhole motor shaft 19 , spring 5 is tightened by rings 14 and sub 13 to form the designed potential energy of the compressed spring. This is ensured by the designed gap between the upper end of hub 6 and traverse 9. This provides the transfer of axial vibrations coming from the bit to shaft 19 and then to the drill string. 


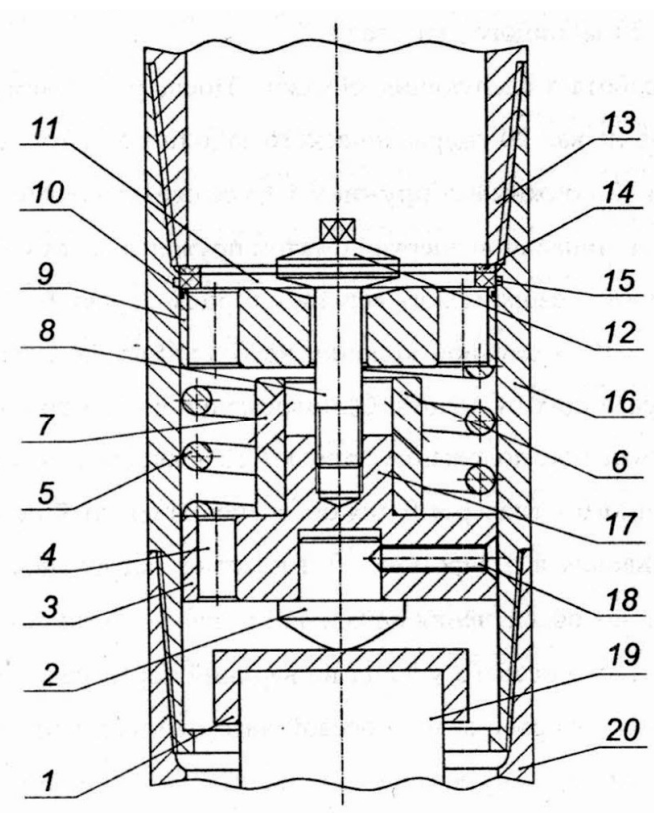

Fig. 1. The scheme of the device for forming weight on bit (DFWOB).

Notation: 1 - toe step; 2 - toe; 3 - housing; 4 - openings; 5 - elastic element, for example, a steel coil spring; 6 - hub; 7 - openings; 8 - rod for mounting valve plate; 9 - traverse; 10 - openings; 11 - saddle built in traverse; 12 valve plate; 13 - working sub; 14 - adjusting rings; 15 - seals; 16 - sub; 17 lug of housing 3 for mounting rod $8 ; 18$ - lock screw; 19 - downhole motor shaft; 20 - downhole motor housing

Simultaneously with the compression of spring 5 , the initial position of valve plate 12 in the opening of valve saddle 11 built into traverse 9 is set to provide the designed average pressure difference in openings 10 and the valve integrated in traverse 9. This provides the designed initial value of the additional hydraulic axial force on the upper end of shaft 19 . Next, the operation of the device and the method of forming WOB will be regarded for the case of drilling a well on its horizontal or inclined section.

During the feeding of the drill string to the bottomhole, the axial force is transmitted from the drill string through sub 13 and rings 14; traverse 9 is moved towards downhole motor shaft 19. Spring 5 is compressed, the clearance between traverse 9 and hub 6 is reduced. Simultaneously with this process, the transmission of axial vibrations from the motor shaft to the drill string is intensified via toe step 1, toe 2, housing 3, hub 6 , traverse 9 and rings 14 . As a result, the frictional forces between the drill string and the walls of the borehole decrease, the drill string moves more freely to the bottomhole and the designed value of the WOB is formed faster.

At the end of the drill string feed to the bottom, valve plate 12 is in its upper position relative to traverse 9 . The gap between hub 6 and traverse 9, and the hydraulic axial force on the motor shaft from the pressure drop effect in the drill string become minimal. At this time, the range of axial vibrations transmitted from the upper end of the shaft to the drill string is the widest, and the WOB is maximal and it is transferred to the bit with a higher efficiency than without the proposed device.

As the bottomhole breaks down, in the time interval between the drill string feeds to the bottom, shaft 19 and valve plate 12 are displaced toward the bottomhole; spring 5 is decompressed, the gap between traverse 9 and hub 6 is increased, and the range of vibrations transmitted to the drill string from the end of the motor shaft is narrowed. At the same time, these vibrations continue affecting on the drill string lying on the bottom wall of the borehole, mainly with increased amplitudes. The lower part of the drill string continues shifting to the bottomhole and creating WOB. At the same time, between the drill string feeds, when rod 8 and plate 12 shift to the bottomhole, the gap for the liquid flow through the valve decreases, and the hydraulic axial force on traverse 9 and further to motor shaft 19 increases, and the flow ripple is increased due to the rigid coupling of valve plate 12 and toe 2 of the device.

Thus, if the time interval between the drill string feeds to the bottom does not exceed the technologically necessary value, the hydraulic axial force generated in the drill string, the force from the compressed spring and the vibrations transmitted to the drill string from the end of the motor shaft compensate at least for a significant part of WOB. Consequently, the process of forming WOB between the drill string feeds to the bottomhole does not stop in comparison with the cases of drilling horizontal sections of a well without the proposed device. Moreover, effective control of the drill string feeding to the bottomhole and the use of DFWOB makes it possible to keep the designed WOB.

Using the proposed device leads to the increase of the average axial loads due to the effect from: the variable axial hydraulic force generated by the operation of the device valve, the spring force and vibrations transmitted to the drill string from the upper end of the downhole motor shaft. Increasing the average value of $\mathrm{WOB}\left(\mathrm{P}_{\mathrm{WOB}}\right)$ between drill string feeds to the bottom will increase the power transmitted from the bit to the bottomhole ( $N_{b i t}$ ) and this will increase the coefficient of power transmission to the bottomhole $\left(K_{N}\right)$ and the rate of penetration (ROP). Besides, the steadiness of WOB will increase the bit lifetime and therefore the mechanical drilling time:

$$
\begin{gathered}
N_{b}=2 \pi \cdot n \cdot P_{W O B} \cdot M_{s}, \\
K_{N}=\left(N_{\text {bit }}+N_{\text {clean }}+N_{\text {fin }}\right) / N,
\end{gathered}
$$

where $M_{s}-$ specific torque of the bit at the bottomhole; $N_{\text {clean }}$ - the power needed to clean the bottomhole of the cuttings; $N_{f i n}$ - hydraulic power consumed to finally wreck the rock partially wrecked by the bit; $N$ - the total power generated on the surface.

The more stable operation of the bit will result in more effective stabilization of the well direction and eliminate 
correctional work when drilling horizontal sections of the wells.

The efficiency of the DFWOB largely depends on the following factors: 1) pressure differential in the mud stream flowing through the calibrated openings 10 and through the openings in the valve; 2 ) the magnitude of the axial force of the spring transmitted to the downhole motor shaft; 3) spring 5 vibration mode.

When the valve is fully closed, the hydraulic force is defined as follows:

$$
F_{h}=\left(S_{t r}-S_{h}\right) \cdot P_{d}
$$

where $S_{t r}-$ cross sectional area of the DFWOB defined by the traverse diameter; $S_{h}$ - area of the openings $10 ; P_{d}-$ pressure differential in the mud stream flowing through the calibrated openings 10 .

Pressure differential $P_{d}$ can be calculated in accordance with the fluid flow through the openings. If the openings 10 are not equipped with jet nozzles, the resistance coefficient in such openings should be taken no more than 0.82 .

The value of the self-resonant frequency of cylindrical springs without regard to their mass (i.e. such springs which can be successfully used in DFWOB) can be calculated as follows:

$$
f_{s}=\frac{d_{s} a_{i}}{2 \pi^{2} D_{s}^{2} m_{s}} \sqrt{\frac{g \cdot G_{e}}{2 \gamma_{s}}},
$$

where $f_{s}$ - spring self-resonant frequency; $d_{s}-$ the diameter of the spring turn; $a_{i}=i \pi, i=1,2, \ldots-$ the order of the harmonics; $g$ - gravitational acceleration; $\gamma_{s}$ - specific weight of the spring material; $D_{s}$ - diameter of the spring; $G_{e}$ - modulus of elasticity of the spring material; $m_{s}-$ number of spring turns.

For a steel cylindrical ("massless") spring with $m_{s} \leq 4$, there is:

$$
f_{s}=1.15 \cdot 10^{2} \frac{d_{s} a_{i}}{D_{s}{ }^{2} m_{s}}
$$

A typical choice has the following parameters: $d_{s}=2 \mathrm{~cm}$; $m_{s}=4 ; D_{s}=10 \mathrm{~cm} ; a_{i}=\pi / 2$. In this case, the lowest frequency will be $135 \mathrm{~Hz}$. This can be dangerous if the downhole turbine motor (for example, ZTSSH-195) is operated with the rotation frequency $n=360 \mathrm{rpm}$.

\section{THE DESIGN OF THE BIT CUTTER}

Another way of autonomous wellbore management optimization is the improvement of the bit design [12, 13].

The research taken earlier considered using a polycrystalline-diamond-compact (PDC) bit that can self-adjust its depth-of-cut (DOC)-control characteristics to the constantly changing drilling environment [14]. Also the ways of changing the shape of the bit teeth, their location on the cone, and the shape of cutters vertices were researched. This was mainly aimed at increasing the depth of the indentation of the bit teeth in the rock. Indentation depth is usually less than 3 $\mathrm{mm}$ and limited in any rock type by its wrecking method and the tool toughness. The main drawback of the modern bits teeth is the shape of the rock-destroying vertices of the teeth. It is adapted mainly for the destruction of the rock by indenting the vertices, i.e. the most power-consuming method. In case if small indentation depth most forms of the vertices do not make any difference of the used method of rock destruction. Shifting and shearing of the rock are attendant processes. The positive effect of vertices interference for the fracture of the rock between the teeth during the stress waves in it is excluded. The options of teeth arrangement on the cone with single vertices are limited.

There are drill bits with milled teeth or plugged teeth. The variety of cutters is the consequence of working surface shape of the teeth which, depending on the requirements, are performed with differently rounded or pointed vertex.

In some works it is assumed that the teeth of the cutter penetrate into the rock by $3 / 4$ of its height. In fact, in isotropic rocks of medium and high hardness they cannot be pressed more than by the value of the axial elastic deformation of the rock or by the magnitude of the compression of the stress kernel. In the process of drilling a well, the volume of the fracture zone for one tooth interaction with the bottomhole is less than expected, and the shift of the rock as well. That is why the bits are used which have cutter axes coerced to the bit axis, but this reduces the life of the roller supports.

When using cutters of known designs, the effect of the stress fields interaction is not realized which arises when the teeth are pressed into the rock. To do this, the vertices of the teeth heads should be at a distance of about $8 \mathrm{~mm}$ from each other which is almost impossible to with the inserted due to reducing the strength of the cutter. For the same reason, the area of simultaneous force contact of the teeth of all bit cutters with a bottomhole is limited, and therefore the power of some downhole motors, for example, screw positive displacement motor (PDM), is only partially used. The effectiveness of the tooth's work on the rock shifting is also low because the amplitude of the movement of the rock-breaking vertex of the tooth is often less than necessary for carrying out the second shock leap for the rock to be destroyed. At the same time, the stresses of the tooth vertex are great enough to chip it.

The contact area of the cutter tooth with the bottomhole is limited by the number of teeth that can be placed on the bit; that is why, the power of some downhole motors, for example, PDM remains unclaimed. 
The technical task is the creation of a roller cutter with an increased service life efficiently affecting the rocks.

The task of increasing the diversity of the tooth bit is solved by the fact that the weapon elements are made with several (two or more) rock-breaking vertices in the cutter bit, containing a body with such elements as milled teeth or plugged-in teeth.

The corrupting vertices of the elements can be made with different departures over the outer surface of the roller cutter, with a difference in the departures of the vertices of at least the minimum amplitude of the axial vibrations of the bit, and the efficiency of rock destruction will increase due to the simultaneous contact of closely located adjacent vertices with it and due to an increased shear in the rock at the bottom of the well.

For better working-in of the working surfaces of cutter elements to the rock surface to be destroyed, they can be made with inserts of less durable plastic flexible material pressed into the teeth or heads of the teeth between the stronger teeth.

In the proposed design, the use of the cutter makes it possible to increase the local zone of the cutter and the rock interaction and increase the volume of the rock destroyed due to realization of the effect of simultaneous intense force contact of several vertices of the tooth with the bottomhole, and also to realize the effect of the second shock leap of rock failure.

Fig. 2 shows some designs of teeth. It is clearly seen in fig. 2 -b that vertices 4 and 5 have different height over the cone body.

During the process of drilling with a downhole motor, when the axial force is created on the bit and rolling of cutters on the bottomhole, the cutter (milled teeth or insertion teeth) strongly contacts the rock. The axial force on the bit is distributed to the teeth and their vertices simultaneously contacting the bottom of the well.

With single-vertex teeth, when the force is transferred to the tooth, the initial chip of the rock occurs, usually in a small volume, after that the vertex of the tooth is pressed into the rock and creates there a core of stresses. The rock in the core is crushed or elastically deformed with a significant part of the energy being dissipated in the rock. The crushing of the rock in the core and its elastic deformation consumes a large amount of energy transferred to the bit from the motor. In addition, the amount of energy transferred to the rock is limited by the time of contact of the tooth with the rock. The rock indent, especially in an isotropic medium or high hardness, is frequently produced after repeated axial impacts of the teeth on it. When the tooth hits the groove of the bottomhole, the energy of the motor is consumed even less efficiently, and the joint influence of the adjacent teeth on the rock destruction is reduced to zero. This also fully applies to the operation of milled teeth.

With multi-vertex teeth, it is possible to arrange them so that the effect of simultaneous joint influence of several rockdestroying peaks is used more fully.
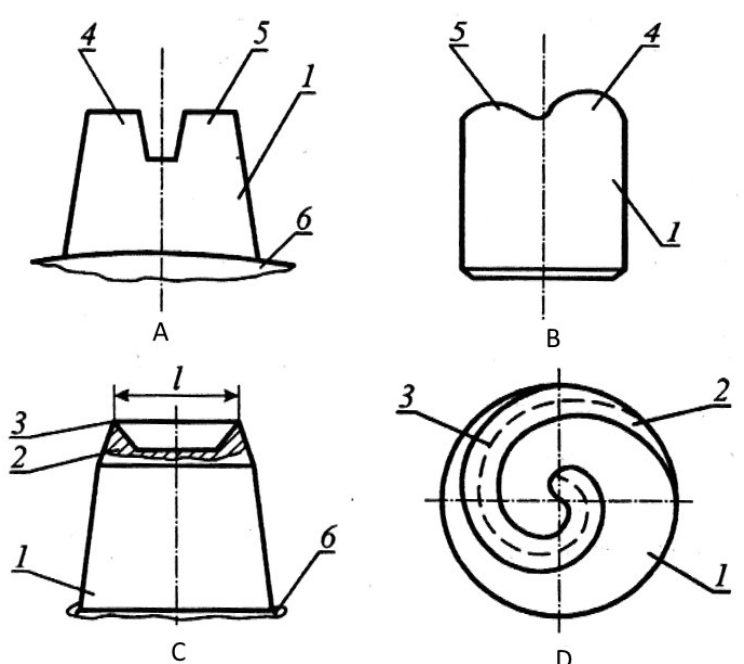

Fig. 2. Teeth design of the roller bit

A - two-vertex milled tooth; B - two-peaked hard-alloy tooth; C - a tooth with the rock-breaking vertex located along the perimeter of the working part of the tooth; D - hard-alloy tooth with a rock-breaking spiral vertex on the upper part of the tooth. 1 - the tooth's body; 2 - rock-breaking vertex of the tooth with working edge $3 ; 4,5$ - rock-breaking vertices of the tooth (with a double-vertex tooth); 6 - the body of the bit cutter.

When the force action of several vertices of the teeth is simultaneously applied to the bottomhole, the maximum stress is simultaneously achieved at the whole contact zone of the vertices, including zones between them. The rock chipping takes place over a larger area and in a larger volume than with single-vertex teeth. In this case, the number of bottomhole hits will increase and the height of the bottomhole protrusions will decrease. Operating the drilling process that way using such bit milling elements, it is possible to make more perfect use of the potential of low-speed drilling with increased WOB with lower power costs for shredding the rocks at the bottomhole which will increase the ROP.

\section{USING ACOUSTIC FILTERS TO CONTROL THE AMPLITUDE OF MUD FLOW PULSATIONS}

One more way of drilling processes optimization by means of autonomous devices is changing fluid pulsation parameters. It is known that the vibrations of the turbodrill, the bit, and liquid flow excite oscillations with the frequency of the drilling pumps operation.

The oscillation frequency may be different and even proportional to the rotary speed of the turbodrill shaft. It is natural that the oscillations moving towards each other will be summed up and their power, as a function of time, will depend on the ratio of frequencies, amplitudes and phases. Taking into account the irregularity of pumps operation and the oscillations with varying frequency it can be considered that the operation rhythmicity of the system "pump - turbodrill bit" is broken. Obviously, additional uneven operation of the pumps, the turbodrill and the bit results in a certain reduction of ROP per bit. When drilling boreholes for the casing, two 
pumps typically operate with the mud feed of about $55 \mathrm{l} / \mathrm{s}$ and the turbodrill ZTSSH1-240 is used with rotational frequency of $12-14 \mathrm{~Hz}$. In this case the peak pressure within the drill string is about $10 \%$ of the average. Consequently, the decrease of ROP will be about $10 \%$.

When drilling wells for a casing, the use of broadband acoustic filters (surface sound vibration absorbers installed in the manifold) provides a more rhythmic operation of the "pump - turbodrill - bit" system. As shown in the tests conducted at the Tarasovskoye field of the Purpeisk Drilling Administration, it allows one to increase the mechanical drilling speed by $10 \%$ and the ROP per bit by $7-10 \%$.

\section{CONCLUSION}

The paper presents the results of the research on improving management efficiency of deepening directional wells with horizontal sections. A method for forming WOB is provided including the traditional discrete feeding of the drill string to the bottom of the borehole, transferring axial forces from the string to the bit through the body of the hydraulic downhole motor, forming an axial hydraulic force on the downhole motor shaft by creating pressure drops in the flushing unit. The feature of this method is that an additional hydraulic force is generated above the hydraulic downhole motor shaft and transferred to the upper end of the shaft and then to the bit together with a part of the axial force from the drill string through the elastic element.

This method also reduces the frictional forces of the drill string against the borehole wall due to the constant transfer of axial vibrations from the bit to the drill string through the upper end of the downhole motor shaft and also by adjusting the range of vibration parameters transmitted to the string from the motor shaft.

The implementation of the presented method became possible due to the use of the original design of the "device for forming weight on bit" (DFWOB) which is located in a sub between the downhole motor shaft and the drill string.

Experimental studies of this technical solution showed an increase of the average WOB by $30 \%$ between the drill string feeds and the bottomhole, which also leads to an increase in the power transferred from the bit to the bottomhole. This increases the coefficient of power transfer to the bottomhole, the efficiency of the drilling method and the ROP.

\section{References}

[1] X. Chen, D. Gao, B. Guo, Y. Feng, "Real-time optimization of drilling parameters based on mechanical specific energy for rotating drilling with positive displacement motor in the hard formation", Journal of Natural Gas Science and Engineering, vol. 35, part A, pp. 686-694, September 2016.

[2] Z. Li, H. Yang, C. Xu, X. Chen, X. Liu, "Bit feed principles and technologies in slide-drilling directional wells", SPE Drilling and Completion, vol. 24, Issue 2, June 2009, pp. 293-300.

[3] S. Jones, C. Feddema, J. Sugiura, "A new steady weight-on-bit tool reduces torque and RPM variations and enhances drilling efficiency and bit/BHA life", SPE/IADC Drilling Conference, Proceedings, vol. 2015January, pp. 379-395.

[4] B. Chmela, N. Gibson, E. Abrahamsen, R. Bergerud, "Safer tripping through drilling automation", IADC/SPE Drilling Conference and Exhibition, 4-6 March, 2014, Fort Worth, Texas, USA.

[5] B. Alotaibi, C. Otalvora, B. William, M.S. Nefai, "Bottom-hole assembly management system (BHAMS)", SPE Annual Technical Conference and Exhibition, Proceedings, vol. 2, pp. 1206-1216, 2014 [ATCE 2014, Amsterdam, Netherlands, 27 October 2014]

[6] H.R. Motahhari, G. Hareland, R. Nygaard, B. Bond, "Method of optimizing motor and bit performance for maximum ROP", SPE/IADC Drilling Conference, Proceedings, vol. 1, 2009, pp. 493-504.

[7] A. Wu, G. Hareland, "Real-time downhole weight on bit (DWOB) automation in directional drilling", SPE Drilling and Completion, vol. 31, issue 4, pp. 286-294, December 2016.

[8] K. Mohan, F. Adil, R. Samuel, "Tracking drilling efficiency using hydro-mechanical specific energy", SPE Brazil Offshore Conference 2011, vol. 1, 2011, pp. 450-461 [Brazil Offshore Conference 2011; Macae, Rio de Janeiro; Brazil; 14 June 2011]

[9] E. Omojuwa, S. Osianya, R. Ahmed, "Influence of dynamic drilling parameters on axial load and torque transfer in extended-reach horizontal wells", SPE Annual Technical Conference and Exhibition, Proceedings, vol. 5, pp. 4092-4105, 2013 [ATCE 2013, New Orleans, LA, United States, 30 September 2013].

[10] T. Pink, W. Koederitz, A. Barrie, D. Bert, D. Overgaard, "Closed loop automation of downhole weight on bit improves sliding performance and reduces conservatism in unconventional horizontal well development", Natural Gas Industry, vol. 33, Issue 12, 2013, pp. 94-98.

[11] A. Al Ali, S. Barton, A. Mohanna, "Unique axial oscillation tool enhances performance of directional tools in extended reach applications", Measurement: Journal of the International Measurement Confederation, vol. 44, Issue 4, May 2011, pp. 642-652.

[12] S. Barton, H. May, S. Johnson, "Gauge, cutting structure, torque control components - what really counts for optimal tool face control with FC drill bits?", Journal of Canadian Petroleum Technology, vol. 48, Issue 6, June 2009, pp. 44-49.

[13] J. Schroder, A. Al Darwaish, J.W. Richards, M. Di Pasquale, M. Mohamed, J. Yorty, "Extending bit life through bearing innovations", SPE/IADC Drilling Conference, Proceedings, vol. 2, pp. 932-937, 2014 [SPE/IADC Drilling Conference and Exhibition 2014; Fort Worth, TX; United States; 4 March 2014].

[14] J.R. Jain, G. Ricks, B. Baxter, C. Vempati, V. Peters, et al. "A step change in drill-bit technology with self-adjusting polycrystallinediamond-compact bits", Journal of Natural Gas Science and Engineering, vol. 35, pp. 686-694, 1 September 2016. 